\title{
O encontro entre João Clímaco Bezerra e a Revista Brasiliense: a trajetória de um intelectual de província*
}

\author{
The encounter between João Clímaco Bezerra and the Revista Brasiliense: the \\ trajectory of an intellectual of province
}

Alexandre Barbalho

\begin{abstract}
Doutor em Comunicação e Cultura Contemporâneas pela
\end{abstract} UFBA e pós-doutor em Comunicação pela Universidade Nova de Lisboa

Resumo: $\mathrm{O}$ artigo analisa o recrutamento por parte da Revista Brasiliense, publicação sediada em São Paulo que circulou entre 1955 e 1964, do literato cearense João Clímaco Bezerra (JCB), objetivando entender o espaço de possíveis que permitiu a circulação de um escritor de província para além das fronteiras regionais e sua participação em um projeto político-cultural de caráter nacionaldesenvolvimentista e cujos principais articuladores eram nomes consagrados da intelectualidade brasileira. Como recurso metodológico, a partir da sociologia bourdieusiana, se remontou a trajetória de JCB e se elaborou o conjunto de capitais (cultural, social e intelectual) alcançados pelo escritor. Buscou-se, dessa forma, estabelecer os ritos de instituição e nominação que construíram a identidade social do agente analisado, os mecanismos de consagração, as posições ocupadas nos espaço sociais onde transitou e por meio das quais estabeleceu suas redes de sociabilidade e de filiação.

Palavras-chave: Intelectual; Província; Trajetória; Ceará; Revista Brasiliense; João Clímaco Bezerra.
Abstract: The article analyzes the recruitment by Revista Brasiliense, a publication based in São Paulo that circulated between 1955 and 1964, of Ceará literary writer João Clímaco Bezerra (JCB), aiming to understand the space of possibilities that allowed the circulation of a provincial writer beyond regional borders and their participation in a nationaldevelopmentist political-cultural Project and whose main articulators were consecrated names of Brazilian intellectuality. As a methodological resource, from Bourdieusian sociology, JCB's trajectory was traced and the set of capitals (cultural, social and intellectual) reached by the writer was elaborated. In this way, we sought to establish the rites of institution and naming that built the social identity of the analyzed agent, the mechanisms of consecration, the positions occupied in the social spaces where he moved and through which he established his networks of sociability and affiliation.

Keywords: Intellectual; Province; Trajectory; Ceara; Revista Brasiliense; João Clímaco Bezerra.

\footnotetext{
* O autor agradece a contribuição dos/as pareceristas anônimos/as que contribuíram para a versão final do artigo.
} 
A Revista Brasiliense $(R B)$, uma publicação bimensal sediada em São Paulo e que circulou entre 1955 e 1964, reuniu em torno de si nomes consagrados da intelectualidade brasileira, com predominância daquela nascida ou radicada em São Paulo, como o historiador Caio Prado Júnior ${ }^{1}$, ou no caminho provável da consagração por conta dos capitais herdados e dos já adquiridos naquele momento, caso do jovem sociólogo Fernando Henrique Cardoso². Ainda que publicasse textos de cunho literário, tratava-se antes de um periódico focado em discutir a realidade brasileira, a partir de uma perspectiva nacionalista e de esquerda, próxima ao Partido Comunista Brasileiro (PCB), apesar de, em momento algum, ter sido veículo de divulgação oficial desse ou de outro partido.

Pode-se entender a revista como meio para a intervenção de um grupo de agentes engajado em marcar sua posição nas disputas políticas em curso no país, orientadas em grande parte pela adesão ou oposição ao ideário nacionaldesenvolvimentista. Desse modo, não atuavam somente como historiadores, sociólogos ou mesmo literatos, mas como intelectuais, entendendo estes, segundo Gisèle Sapiro (2009), como produtores culturais que participam ativamente da esfera pública e de seus debates e embates, portanto, da produção ideológica de seu tempo, situando-se o campo intelectual na interseção entre os campos político e cultural. Como sugere Bourdieu (1999), o intelectual sai do campo cultural com a autoridade ali adquirida para exercer uma ação política.

A $R B$ seria, assim, uma forma específica de engajamento intelectual que se apoiava no capital simbólico de seus integrantes, o que explica o porquê da revista ter, em seu número inaugural, lançado um manifesto, um "editorial declaração", seguido da assinatura de 45 apoiadores. Desse grupo, somente oito viviam fora de São Paulo e entre eles o literato cearense João Clímaco Bezerra (JCB). Levando em consideração a lógica hierárquica e de poder do campo intelectual brasileiro, como entender a presença de um escritor atuante na província nesta seleta associação? Que espaço de possíveis

\footnotetext{
${ }^{1}$ Nascido em São Paulo em 1907, Caio Prado Júnior tinha publicado, entre outras obras, Formação do Brasil Contemporâneo (1942), que alcançou impacto relevante desde o seu lançamento, principalmente entre jovens intelectuais (ZOREK, 2007), e sido eleito deputado constituinte em 1948 pelo Partido Comunista do Brasil.

2 Nascido no Rio de Janeiro em 1931, oriundo de família de militares e políticos atuante desde o Império, Fernando Henrique Cardoso era professor da Universidade de São Paulo, onde iniciou suas atividades em 1952 como Primeiro Assistente da cadeira de História Econômica Geral e do Brasil e participou da pesquisa "O processo de industrialização em São Paulo" realizada em 1953. Recém-efetivado professor, elegeu-se para o Conselho Universitário, cargo que indicava o capital social relevante que conseguia mobilizar no início de carreira (GARCIA JÚNIOR, 2004).
} 
permitiu a circulação de JCB para além das fronteiras regionais e seu recrutamento por parte de um projeto político-cultural nacionalista?

O que se busca neste artigo é dar conta dessa problemática remontando a trajetória de JCB com o cuidado de não cair na ilusão retórica dos relatos bio ou autobiográficos, como adverte Bourdieu (1986; 2005). Procura-se, dessa forma, estar atento aos ritos de instituição e nominação que construíram a identidade social do agente analisado, aos mecanismos de consagração, às posições ocupadas nos espaço sociais onde transitou, por meio das quais estabeleceu suas redes de sociabilidade e de filiação (política, cultural, geracional etc).

$\mathrm{O}$ artigo se organiza em três seções seguidas das considerações finais. $\mathrm{Na}$ primeira, se analisa o processo de amealhamento de recursos (cultural, social, político) que JCB detinha no momento que foi recrutado para a $R B$. Na seção seguinte, se situa o lugar da $R B$ nos embates em curso no campo intelectual brasileiro dos anos de 1950. E na terceira, é feito um cruzamento entre as trajetórias de JCB e da $R B$ de modo a entender como se deu o encontro entre ambas.

\section{João Clímaco Bezerra e a irresistível fascinação pelas letras}

João Clímaco Bezerra, nasceu em Lavras da Mangabeira, interior do Ceará, em 1913, descendente de uma família de comerciantes e agricultores, tendo chegado a atuar no comércio em sua cidade natal para sustentar os irmãos estudantes em Fortaleza, após o falecimento do pai em 1930. Mudou-se para a capital somente em 1940 onde se empregou na Secretaria de Educação e finalizou o curso secundário no colégio São João que, a despeito de ser uma das melhores escolas da rede privada da cidade, não era o principal centro de formação das elites, posto ocupado pelo Liceu. No mesmo ano, iniciou sua atuação jornalística, atuando nos anos 1950 nos jornais Unitário e Correio do Ceará, dos Diários Associados, nos quais publicava crônicas, crítica literária e o editorial. Iniciou também muito cedo sua carreira docente em colégios da cidade.

Como opção usual para quem desejava fazer carreira no mercadejo e seguir sua ascendência familiar, formou-se como contador pela Escola de Comércio Padre Champagnat da qual Antônio Martins Filhos era diretor e proprietário. Após o término do curso técnico, entrou para a Faculdade de Direito na qual se bacharelou em 1950, título que possibilitou sua entrada como professor na Faculdade de Ciências Econômicas. Como sugere a nota biográfica que acompanha uma de suas obras, JCB 
sentia uma "irresistível fascinação pelo comércio. Mas terminou funcionário público e bacharel, como toda gente" (CÂMARA, 1999: 52).

Como se observa, não foi como herdeiro ou por conta de títulos conquistados em instituições de ensino consagradas que JBC conseguiu vencer as barreiras de entrada no campo intelectual cearense. O que soube foi aproveitar as oportunidades de atuação oferecidas por esse campo (chances objetivas) a um jovem aspirante ao posto de escritor (esperança subjetiva), e, na sequência, ao publicar suas obras, conquistar o reconhecimento local e, de algum modo, nacional.

Quando foi recrutado pela $R B$ em 1955, JCB tinha publicado pelas Edições Clã a novela Longa é a Noite (1951) e pela editora José Olympio (J.O.) os romances Não Há Estrelas no Céu (1948) e Sol Posto (1952). É preciso dimensionar o que significava ser um autor da J.O. naquele momento. Gustavo Sorá contextualiza que, entre 1930 e 1950, a editora desempenhou um papel de importância considerável na unificação simbólica do Estado e da cultura nacionais. Fazer parte de seu catálogo, cujas obras eram tidas como "autenticamente brasileiras", era o desejo de todo autor, pois bastava essa marca para que ocorresse a consagração no campo.

Segundo o depoimento do escritor Artur Eduardo Benevides (apud BEZERRA, 1997), que converge com o depoimento que JCB deu em 1956 ao jornalista Renard Perez do Correio da Manhã, o aspirante a romancista entregou os originais de Não Há Estrelas no Céu para apreciação do crítico Otto Maria Carpeaux, com quem travou relações quando este foi à Fortaleza em 1946 para participar do I Congresso Cearense de Escritores (CCE). Carpeaux aprovou o romance e convenceu o cearense a ir ao Rio de Janeiro para tentar sua publicação pela J.O.. O editor, por sua vez, submeteu a obra à avaliação de Graciliano Ramos que não apenas recomendou sua publicação como comentou em seu círculo de relações sobre a qualidade do romance.

Como situa Perez (1956), o livro foi tido como uma revelação do romance nacional e tornou-se um sucesso de mercado e de crítica, tendo a edição se esgotado em menos de quatro meses. A obra recebeu mais de uma centena de críticas favoráveis, assinadas por nomes consagrados da literatura brasileira e portuguesa, entre os quais Rachel de Queiroz, José Lins do Rego, Érico Veríssimo, Sérgio Milliet, Herman Lima, Jorge Amado, Tristão de Atayde, Miguel Torga e Ferreira de Castro (PEREZ, 1956; CÂMARA, 1999; MACEDO, s/d).

$\mathrm{Na}$ "Letras e Livros" do Correio da Manhã, umas das colunas literárias mais lidas na imprensa carioca e sob responsabilidade de José Condé (TAVARES, 2013), lê- 
se que quando estreou em 1948, JCB era um nome totalmente desconhecido no Rio de Janeiro, “entretanto, da noite para o dia, os nossos principais críticos tomavam conhecimento de sua presença, o seu livro passava a ser considerado como um dos melhores do ano" (CORREIO DA MANHÃ, 1952a: 10)³.

Ser publicado por uma editora de circulação nacional como a J.O. garantiu que seus romances chegassem em outros estados brasileiros, para além de São Paulo e Rio de Janeiro, e fossem objeto também da crítica literária nas províncias. É o caso, por exemplo, de Heron de Alencar, crítico do jornal soteropolitano A Tarde. Heron, que seria colega de JCB na fundação da $R B$, escreveu sobre o romancista em 1948, ano de publicação de Não Há Estrelas no Céu, na sua coluna "Caleidoscópio", na qual traçava perfis biobibliográficos e fazia breves análises da produção de escritores nacionais (SANTANA, 2003).

No contexto local, JCB integrou o que a crítica literária denomina de quarta fase da literatura cearense ou Geração 45 (BARBALHO; BARROSO, 1998), responsável pela criação do Grupo Clã. Embora não detivesse lugar de liderança entre seus pares, participou ativamente da vida intelectual cearense desde o início dos anos de 1940, ocupando os espaços possibilitados por um momento de efervescência político-cultural no país e no estado.

Escreveu artigos para a revista Valor, um "Mensário de Ciências, Letras e Informações", criada pela editora, impressora e livraria "Fortaleza" em 1938, cujo proprietário era o mesmo Martins Filho da Escola Padre Champagnat. A Valor circulou por quase 10 anos, tendo sido editados 29 números, com tiragens que variavam de 1.500 a 2.000 exemplares $^{4}$. O periódico desempenhou um papel importante no ambiente intelectual da província ao dar visibilidade a seus colaboradores, tanto internamente, quanto fora do Ceará. Como constata Erich Oliveira, o objetivo da revista era "destacarse como difusora da produção intelectual" e "se colocar no meio letrado nacional", ao buscar "interlocução com a produção dos grandes centros do período, divulgando novidades do mercado livreiro, resenhando autores de circulação nacional e promovendo debates literários e científicos por meio de suas páginas” (OLIVEIRA, 2019: 51).

\footnotetext{
3 No mesmo jornal, a livraria Independência anunciou em novembro de 1952 as novidades literárias nacionais e estrangeiras, entre as quais Sol posto (CORREIO DA MANHÃ, 1952b: 2).

${ }^{4}$ A partir de 1946, a revista passou a ser publicada pelo Instituto do Ceará.
} 
Nesse periódico, JCB dividiu espaço com intelectuais cearenses consagrados localmente, como Demócrito Rocha e Florival Seraine, e nacionalmente, a exemplo de Djacir Menezes, Rachel de Queiroz, Antônio Sales e Clóvis Beviláqua, e com estreantes, como ele, que depois se reuniriam no Grupo Clã: Fran Martins, Antônio Girão Barroso, Eduardo Campos, José Stênio Lopes, Braga Montenegro, Eduardo Campos, entre outros.

O escritor esteve envolvido na organização e participou do I Congresso de Poesia do Ceará em 1942, que discutiu, entre outras questões, as dificuldades de se publicar e vender livros no estado. Como consta em seu depoimento a Perez, foi o poeta Antonio Girão Barroso, com quem tinha travado relações pessoais quando de sua chegada em Fortaleza, que o convidou para participar da comissão organizadora do evento. Com isso, JCB passou a conviver de forma mais próxima com aquele grupo de escritores. A ocasião foi pensada, por seus organizadores, como uma atividade de repúdio à guerra. Ao lado de jovens literatos, como Eduardo Campos, que leu o manifesto do congresso de costas para o público, e Artur Eduardo Benevides, participaram escritores da geração modernista cearense como Mário Sobreira de Alencar (Mário de Andrade do Norte) e Filgueiras Lima, bem como figuras reconhecidas em outros setores da intelectualidade e da política estaduais.

JCB também foi presença ativa no I Congresso Cearense de Escritores (CCE) realizado em 1946. Como desdobramento do I CBE, o I CCE foi promovido pela Seção Ceará da ABDE, presidida por Fran Martins e da qual Clímaco era tesoureiro, e obteve apoio de instituições consagradas e consagradoras do campo cultural local, como o Instituto do Ceará e a Academia Cearense de Letras. Na avaliação do escritor Mozart Aderaldo, o I CCE se notabilizou por suas "importantíssimas teses" que "foram expostas, criticadas e defendidas, para, afinal, adotar-se a opinião do consenso"s.

Em sua palestra no I CCE, intitulada "Considerações em Torno do Provincianismo e do Centralismo na Literatura Brasileira", JCB fez a defesa do intelectual como alguém capacitado a guiar a população, ou melhor, o "homem comum”, que seria incapaz de estabelecer um “norte exato, prudente e eficaz" diante da

\footnotetext{
${ }^{5}$ Uma delas, de autoria de Raimundo Girão, defendia a criação de uma Secretaria Estadual de Cultura, o que foi ocorrer vinte anos depois no governo de Plácido Aderaldo Castelo e que teve Girão como seu primeiro titular. A criação do órgão resultou da proximidade entre o campo intelectual e o campo político cearenses, como revela a multiposicionalidade de agentes nos dois campos. Assim, Castelo era membro do Instituto Histórico e Geográfico do Ceará e Girão tinha sido prefeito de Fortaleza (BARBALHO, 1998).
} 
diversidade de ideias que há no mundo. O elitismo que guia o raciocínio do escritor é explícito:

Qualquer noviço de ginásio, qualquer operário mais letrado, qualquer homem do povo quer ter a vaidade de ter ideias, quase sempre superficiais, e se enchem de ideias alheias, às vezes não menos rasteiras, colhidas através do livro, do jornal, do rádio, da cátedra, das tertúlias mentais nos grêmios e associações e, sem poder combiná-las, nem aprofundá-las, para extrair delas o verdadeiro substrato, acabam indo na onda, como mariposas (BEZERRA apud ALVES, 2015: 59).

Em 1947, por meio de sua atuação junto à ABDE-CE, da qual foi vicepresidente nas diretorias de 1948 e 1949, JCB integrou a delegação cearense do II Congresso Brasileiro de Escritores em Belo Horizonte. Entre os integrantes, encontravase Raquel de Queiroz, uma das fundadoras da ABDE e que participou da representação do estado no I CBE, junto com Raimundo Magalhães e Herman Lima. A escritora era reconhecida nacionalmente desde a década de 1930, quando publicou seu primeiro romance, O quinze (1930), recebeu o Prêmio de Literatura da Fundação Graça Aranha e, morando no Rio de Janeiro, já vivia de suas crônicas publicadas na imprensa (MELLO, 2019). No Congresso, que teve a participação de Antônio Cândido, Edgar Carone, Jorge Amado, Dalton Trevisan e José Paulo Paes, entre outros, JCB participou da comissão de direitos autorais, uma das pautas centrais do encontro.

Porém, o mais importante engajamento político-cultural de JCB foi no Grupo Clã (Clube de Literatura e Arte), inicialmente denominado Clube de Literatura e Arte Modernas (CLAM), do qual foi um dos fundadores em 1943. O agrupamento não tinha a intenção de reproduzir o modelo das agremiações e academias de literatos, como espaço de reuniões meramente sociais, e sim de assumir uma participação ativa nos rumos da cultura cearense e mesmo brasileira, daí a atuação de vários de seus membros nos encontros estaduais e nacionais de escritores e na ABDE-CE. É ilustrativo, a esse respeito, que para Mozart Aderaldo (1986), ele próprio integrante do grupo, o Clã tenha sido não uma agremiação de prosadores e poetas, e sim um "movimento cultural".

O grupo estabeleceu relações com jovens teatrólogos (Eduardo Campos e Artur Eduardo Benevides), artistas plásticos (Antônio Bandeira, Aldemir Martins, Mário Barata, entre outros), reunidos na Sociedade Cearense de Artes Plásticas (SCAP) - que 
também possuía uma presença ativa no cenário cultural da cidade -, e integrantes do movimento cineclubista de Fortaleza, todos interagindo dentro de uma mesma rede de sociabilidade intelectual, de modo que a SCAP chegou a ser dirigida por integrantes do Clã (BARROSO, 1998; PEREIRA, 2017; SILVA, 2015).

Também era intenção do grupo atuar no mercado editorial por meio de uma editora que publicasse os escritos de seus membros. Como narra Aderaldo (1981), foi em uma reunião da ABDE-CE que surgiu a ideia de fundar uma editora e distribuidora para dessa forma enfrentar o "principal problema dos intelectuais de província", a distribuição de seus livros, pois estavam "todos ilhados e sentindo necessidade de publicar seus trabalhos no eixo Rio-São Paulo, sem o que continuarão desconhecidos" (ADERALDO, 1981: 09). Dessa decisão resultaram as "Edições Clã" que iniciaram suas atividades em 1943 publicando Aguas Mortas, o primeiro livro de contos de Eduardo Campos.

Dentro desse projeto editorial, o Clã publicou, de 1946 a 1981, uma revista homônima, que teve seu número inaugural dirigido por JCB, Antônio Girão Barroso e Aluízio Medeiros. Esse número 0, de caráter experimental, não alcançou grande repercussão e o periódico ficou suspenso até ser retomado em fevereiro de 1948, com a publicação do número 1, agora sob direção de Fran Martins e Aluízio Medeiros, e tendo JCB como participante do Conselho de Redação. De existência longeva, o grupo e a revista foram os responsáveis, na avaliação de Sânzio de Azevedo (1982), por consolidar o modernismo no Ceará. A revista publicava vários gêneros literários como poesia, ensaio, novela, biografia, além de textos das Artes e das Ciências Humanas ${ }^{6}$. Foi no número 0 da Clã que JCB publicou o primeiro capítulo de seu romance Não há estrelas no céu e no n. 11, em 1951, sua novela Longa é a noite.

Segundo Maria Auxiliadora Farias, a Clã dava um grande espaço para os "novos talentos da terra" e o esforço era o de "projetar seus escritores, não apenas para o Ceará, mas para o Brasil, proporcionando uma maior aproximação com os intelectuais do país" (FARIAS, 2003: 60). Os resultados, nesse sentido, foram satisfatórios, pois o periódico foi resenhado e comentado em vários jornais brasileiros. Um dos resenhadores foi

\footnotetext{
${ }^{6}$ A aproximação com as Ciências Humanas é compreensível, pois a maioria dos integrantes do grupo era bacharel em Direito e uma parte deles atuava como professor, inclusive no ensino superior (Faculdades de Direito, de Economia e de Filosofia), e/ou jornalista. Como situa Maria Auxiliadora Farias (2003), a docência nos cursos superiores foi um importante trunfo de ascensão profissional e social, que se expressava nos títulos outorgados pelas instituições de ensino, além dos cargos e funções administrativas gratificadas. JCB, por exemplo, atuou como jornalista e lecionou na Faculdade de Ciências Econômicas e na Faculdade de Filosofia do Ceará e exerceu a função de Técnico em Educação.
} 
Sérgio Milliet que ressaltou em O Estado de São Paulo o "esforço dos jovens cearenses na hora atual da literatura brasileira" (MILLIET apud FARIAS, 2003: 62). Vale lembrar que Milliet, como dito anteriormente, iria compor o "núcleo dirigente" da $R B$.

Com isso, a revista tornou-se um instrumento de conexão e divulgação de escritores cearenses com o restante do país, inserindo-os em uma rede mais ampla de recepção junto ao público e, principalmente, entre os pares. Para tanto contou com um grupo de "representantes" em vários estados: Martins D’Alvarez (Rio de Janeiro), Domingos C. da Silva (São Paulo); Mauro Mota (Pernambuco); Wilson Rocha (Bahia); Bueno de Rivera (Minas Gerais); Aldo Morais (Amazonas); Haroldo Maranhão (Pará); Bandeira Tribuzi (Maranhão); Veríssimo de Melo (Rio Grande do Norte); e Dalton Trevisan (Paraná), além de colaboradores e correspondentes, tais como Fernando Ferreira Loanda, Ledo Ivo, José Sarney Costa, Tulo Hostilio Montenegro e Jorge Mendauar.

Representando o que havia de "novo" na produção da província, "os que dela participavam estavam legitimados por uma opinião pública de reconhecida expressão" (FARIAS, 2003: 62). Como sintetiza Oswald Barroso (1998), o Clã desempenhou o papel interno de "núcleo dinamizador e renovador dos meios culturais cearenses" de modo que todas as principais instituições culturais do estado tiveram alguém do grupo, muitas vezes em seu processo de criação, como a Universidade Federal do Ceará e, 1955, que teve como primeiro reitor Antônio Martins Filho, e a Secretaria de Cultura do Estado, como visto. Fora dos limites da província, permitiu a circulação de seus integrantes, participando dos congressos nacionais de escritores, de modo que conquistou reconhecimento nas "rodas literárias" de todo o país.

\section{A Revista Brasiliense e o ponto de vista dos interesses nacionais}

A Revista Brasiliense foi uma publicação da editora e livraria paulista Brasiliense da qual um dos proprietários era Caio Prado Júnior e em cujo prédio se reuniam intelectuais paulistas ou de passagem pela cidade. O periódico herdou a linha nacionalista de outra revista da mesma editora, a Fundamentos, cujo redator-chefe do primeiro número foi Monteiro Lobato e que tinha relação orgânica com o PCB, reunindo em seu "Conselho de Redação" intelectuais do Rio de Janeiro e de São Paulo filiados ao partido (SANTOS, 2016). A RB, cujo editor-responsável era Elias Chaves 
$\mathrm{Neto}^{7}$, se dedicou a publicar artigos críticos sobre a realidade brasileira em uma abordagem nacionalista e marxista, o que não impediu de ter em seu núcleo fundador e entre seus colaboradores vários artistas e literatos, como foi o caso de JCB.

A Fundamentos e a $R B$, entre outras publicações do gênero, inseriam-se dentro da cultura política da época, decorrente do momento de democratização com o fim do governo Vargas, a reconstituição do sistema partidário e o retorno às eleições. Movidos pela defesa da democracia, os intelectuais realizaram em 1945, um pouco antes do fim do Estado Novo, o I Congresso Brasileiro de Escritores (CBE) que reuniu em São Paulo cerca de quinhentos intelectuais, dos quais 150 delegados, além de convidados estrangeiros. O encontro foi uma iniciativa da Associação Brasileira de Escritores (ABE), fundada três anos antes no Rio de Janeiro com o objetivo de debater questões referentes à conjuntura nacional e internacional e à profissionalização do escritor, com destaque para os direitos autorais e a liberdade de expressão (MELO, 2011). Entre seus fundadores, que possuíam diferentes orientações ideológicas, encontravam-se Sérgio Buarque de Holanda, Sérgio Milliet, vice-presidente do Congresso, e Caio Prado Júnior, que se reuniriam uma década depois para outro empreendimento político-cultural, a $R B$. O documento final do I CBE, denominado "Declaração de Princípios", propunha três lutais centrais que seriam, segundo Marisa de Mello, “a legalidade democrática como garantia da completa liberdade; o sistema de governo eleito pelo povo mediante sufrágio universal, direto e secreto; e o pleno exercício da soberania popular em todas as nações" (MELLO, 2019: 64). A declaração fazia a defesa da democracia mas já trazia as palavras de ordem que iriam mobilizar o campo intelectual na década seguinte: "nacionalismo" e "desenvolvimentismo".

O início da década de 1950 testemunhou o surgimento de instituições importantes voltadas a esses temas, tanto à direita quanto à esquerda do espectro ideológico. Ainda em 1949, com a criação da Escola Superior de Guerra, os militares começaram a elaborar sua "doutrina de segurança nacional" visando se contrapor ao comunismo. Por outro lado, em 1953, foi criado o Instituto Brasileiro de Economia, Sociologia e Política (IBESP) no Rio de Janeiro, que editou a revista Cadernos do Nosso Tempo e, na mesma cidade, em 1955 - mesmo ano de surgimento da $R B$-, o Instituto Superior de Estudos Brasileiros (ISEB). Segundo a análise de Daniel Pécaut

\footnotetext{
${ }^{7}$ Elias Chaves Neto atuava como advogado, jornalista, editor e militante político com passagem pelo PCB.
} 
(1990), o ISEB foi sucessivamente, ao longo de sua atuação até 1964, o símbolo do "nacional-desenvolvimentista", do "nacional-populista" e do "nacional-marxista".

Todo esse contexto se expressa no editorial do número 01 da $R B$ que expõe a linha do periódico: congregar os "estudiosos de assuntos brasileiros interessados em examinar e debater os nossos problemas econômicos, sociais e políticos”. Problemas estes que se relacionam com as condições da economia nacional em sua "extrema variedade de níveis e aspectos, provenientes da diversidade dos quadros geográficos e sociais do país e do próprio curso da nossa formação histórica" e que apresenta notável desenvolvimento nos grandes centros urbanos imerso no atraso econômico geral do país e na dependência estrangeira. Dessa forma, o objetivo da RB é analisar essas questões "do ponto de vista dos interesses nacionais, da melhoria das condições de vida do povo e da renovação e dos progressos da cultura, como expressão autêntica da vida brasileira"s.

Mesmo afirmando não ter filiação ou ligação com partidos políticos e seguir somente a orientação de seus redatores e colaboradores - note-se, a esse respeito, como salienta Fernando Limongi (1978), que o manifesto não faz menção à conjuntura política, como o suicídio de Vargas, ou ao sistema partidário vigente -, a $R B$ se propunha a ser, mais do que um meio de divulgação, um "centro de debates e de estudos brasileiros", com a colaboração dos que já estavam habituados ou se dispunham a discutir os problemas nacionais, de modo a "influir sobre a opinião pública levando-a a melhor compreender os problemas que afetam a vida do país" 9 .

Conforme revela Limongi (1978), Elias Chaves Neto, em sua autobiografia, defende que a origem da proposta editorial da $R B$ seria a tese de Caio Prado $\mathrm{Jr}$, "Diretrizes para uma política econômica brasileira", junto à Cátedra de Economia Política na Faculdade de Direito da USP em 1954, onde formulou, pela primeira vez, a noção de "nacionalismo consequente" que fornecia um "novo sentido ao movimento nacionalista", indo além da mera denúncia do abuso das firmas estrangeiras. Com essa afirmação, Chaves Neto desclassifica a produção intelectual nacionalista anterior, como a da Comissão Econômica para a América Latina e o Caribe (CEPAL), criada em 1948,

\footnotetext{
8 Revista Brasiliense, Editorial, n. $1, \quad 1955 . \quad$ Disponível em http://bndigital.bn.br/projetos/expo/caioprado/PDFs/revistabrasiliense.pdf. Acesso em 31.ago.2020. Revista Brasiliense, Editorial, n. 1, 1955. Disponível http://bndigital.bn.br/projetos/expo/caioprado/PDFs/revistabrasiliense.pdf. Acesso em 31.ago.2020.
} 
e do IBESP. De fato, o pensamento de Caio Prado Jr seria a referência quase exclusiva para os principais colaboradores da $R B$.

Como antecipado na introdução, 45 intelectuais assinaram o editorial-declaração de fundação da revista, dos quais oito viviam fora de São Paulo: Acácio Ferreira, Adroaldo Ribeiro Costa e Heron de Alencar (Bahia), Aníbal Machado, Fernando Segismundo e Josué de Castro (Rio), João Clímaco Bezerra (Ceará) e Pinto Ferreira (Pernambuco). Nenhum deles ocupava o Conselho de Redação, o "grupo dirigente" da $R B$, na definição de Marcos Santos Machry (2017), composto no primeiro número, por Caio Prado Junior, principal liderança, Sergio Milliet, Edgard Cavalheiro, Sergio Buarque de Holanda, João Cruz Costa, E.L. Berlink, Álvaro de Faria e Nabor Caires de Brito. Esse grupo seria ampliado posteriormente e os artigos escritos por seus integrantes corresponderiam a quase $40 \%$ do total do textos publicados em todas as edições do periódico. A despeito de reunir intelectuais que já eram referências nacionais, o papel central ocupado por Caio Prado Júnior não implicou em inferioridade ou apagamento do restante do grupo e sim, como defende Machry (2017), na oportunidade para que acumulasse capital social e cultural.

Marcos Machry fala em "coesão política” entre os assinantes do manifesto de fundação da $R B$, o que não implica em homogeneidade teórica, ainda que as diferenças fossem sutis. Para o pesquisador, eram intelectuais que discutiam a questão do nacionalismo e do desenvolvimentismo em diálogo com questões globais, terceiromundistas e latino-americanistas, ou seja, não se restringiam a uma visão paroquial dos problemas brasileiros. Por sua vez, a revista não pode ser desassociada do papel do PCB na cultura, o que se comprova pelo fato de que dos 20 nomes que compuseram a direção e o conselho de redação, treze fizeram parte, em algum momento, do partido. Ou seja, "a trajetória do comunismo no país esteve, a rigor, ligada às biografias dos intelectuais que participaram da publicação" (MACHRY, 2017: 53).

De fato, é relevante a importância do PCB no debate político-cultural do período em tela e a atuação de seus intelectuais, filiados ou simpatizantes, nos diversos espaços de produção simbólica do país. Como defende Albino Rubim, mesmo na clandestinidade, o partido "buscou sempre estruturar durante toda a sua existência uma rede de aparatos culturais que, destinadas a seus militantes e/ou a um público mais amplo, realizou parte significativa de sua intervenção político/ideológica na sociedade brasileira" (RUBIM, 1995: 22). Com o fim do Estado Novo, o PCB estruturou uma rede de comunicação que incluía oito jornais diários e inúmeros semanários editados nas 
principais cidades brasileiras e uma agência de notícias (Interpress), além das revistas, incluindo as de linha editorial voltada para a cultura, como Literatura (1946), a já citada Fundamentos (1948), Horizonte (1951), entre outras. Somavam-se a esta linha de atuação, por exemplo, a edição de livros, com destaque para a coleção "Romances do povo" (Editorial Vitória), e a promoção das artes plásticas com os clubes de gravura e da produção cinematográfica.

Havia também, além da política, uma coesão social entre os membros do grupo dirigente, como revela a prosopografia feita por Machry (2017). Esta sociabilidade comum decorria, salvo exceções, tanto pelos contatos propiciados por meio de vínculos familiares, incluindo a amizade sólida entre famílias tradicionais - como os Prado, os Chaves, os Buarque de Holanda e os Cardoso -, quanto pela convivência e conivência possibilitadas pelo presença nos mesmos espaços acadêmicos, culturais e de lazer de São Paulo (faculdades, teatros, cinemas, livrarias, bares, restaurantes etc).

O papel da $R B$ nesse contexto político-cultural é importante quando se leva em consideração o que Bourdieu diz a respeito das revistas de divulgação acadêmica, mais especificamente Les Temps Modernes La Nouvelle Critique e Esprit, como instituições ao mesmo tempo estruturadas e estruturantes do campo intelectual francês. Assim, sugere-se que o mesmo se deu em relação à $R B$ no caso brasileiro. E seguindo o que indica uma das leis gerais da teoria dos campos - a de que "o espaço das posições ocupadas no campo por indivíduos ou instituições corresponde ao espaço das tomadas de posições"(BOURDIEU, 1999: 21) ${ }^{10}$-, depreende-se que a análise das propriedades dos agentes associados à $R B$ permite entender as tomadas de posição correspondentes dentro do campo intelectual brasileiro. $\mathrm{O}$ esforço da seção seguinte é traçar o encontro da trajetória de JCB com os propósitos da $R B$.

\section{O encontro de JCB com a $R B$}

É possível agora retomar a problemática que orienta a investigação, de modo a: 1. sistematizar os recursos conquistados por JCB e que lhe deram visibilidade para além da província e 2. identificar os interesses que levaram ao seu ingresso na $R B$. No que diz respeito ao primeiro ponto, é possível elaborar três quadros com os capitais cultural, social e intelectual que o escritor cearense acumulou até a metade da década de 1950.

\footnotetext{
10 Tradução livre minha. No original: “"l'espace des positions occupées dans le champ par des individus ou des institutions correspond à l'espace des prises de positions"”,
} 
Quadro I: Capital cultural

\begin{tabular}{|l|l|l|}
\hline Tipo & Período & Repercussão \\
\hline $\begin{array}{l}\text { Artigos na revista } \\
\text { Coeditor do } \\
\text { número inaugural } \\
\text { da Revista Clã de 1940 }\end{array}$ & Local \\
\hline $\begin{array}{l}\text { Colaboração na } \\
\text { revista Clã do }\end{array}$ & $\begin{array}{l}\text { Décadas de 1940 e } \\
1950\end{array}$ & Nacional \\
\hline $\begin{array}{l}\text { Publicação do } \\
\text { romance Não há } \\
\text { estrelas no céu }\end{array}$ & 1948 & Nacional \\
\hline $\begin{array}{l}\text { Publicação da } \\
\text { novela Longa é a } \\
\text { noite do }\end{array}$ & 1952 & Nacional \\
\hline $\begin{array}{l}\text { Publicação } \\
\text { romance Sol posto }\end{array}$ & \\
\hline
\end{tabular}

Quadro II: Capital social

\begin{tabular}{|l|l|l|}
\hline Tipo & Período & Repercussão \\
\hline $\begin{array}{l}\text { Atuação como } \\
\text { jornalista }\end{array}$ & $\begin{array}{l}\text { Décadas de 1940 e } \\
1950\end{array}$ & Local \\
\hline $\begin{array}{l}\text { Integrante do } \\
\text { Grupo Clã }\end{array}$ & $\begin{array}{l}\text { Décadas de 1940 e } \\
1950\end{array}$ & Nacional \\
\hline $\begin{array}{l}\text { Associado da } \\
\text { ABDE-CE }\end{array}$ & Década de 1940 & Nacional \\
\hline
\end{tabular}

Quadro III: Capital intelectual

\begin{tabular}{|l|l|l|}
\hline Tipo & Período & Repercussão \\
\hline $\begin{array}{l}\text { Atuação no Grupo } \\
\text { Clã }\end{array}$ & $\begin{array}{l}\text { Décadas de 1940 e } \\
1950\end{array}$ & Nacional \\
\hline Atuação na ABDE- & Década de 1940 & Nacional \\
\hline
\end{tabular}




\begin{tabular}{|c|c|c|}
\hline $\mathrm{CE}$ & & \\
\hline $\begin{array}{ll}\text { Organização } & \text { e } \\
\text { participação do } & \text { I } \\
\text { Congresso de } & \text { de } \\
\text { Poesia do Ceará } & \end{array}$ & 1942 & Local \\
\hline $\begin{array}{llll}\text { Organização } & & \text { e } \\
\text { participação } & \text { do } & \text { I } \\
\text { Congresso } & & \\
\text { Cearense } & & \text { de } \\
\text { Escritores } & & & \end{array}$ & 1946 & Nacional \\
\hline
\end{tabular}

Devido à importância da revista Clã no contexto local e de suas articulações nacionais, como visto na seção anterior, é importante elencar sua contribuição no periódico até 1955 :

Quadro IV: Contribuição na revista Clã

\begin{tabular}{|c|c|}
\hline Edição & Contribuição \\
\hline Ano I, no 0, dez. 1946. & $\begin{array}{l}\text { Capítulo do romance Não há estrelas no } \\
\text { céu. }\end{array}$ \\
\hline Ano I, no 2, abr. 1948. & $\begin{array}{l}\text { Resenha de Marajó, romance de Dalcídio } \\
\text { Jurandir editado pela J.O. em } 1947 \text {. }\end{array}$ \\
\hline Ano I, no 3, jun. 1948. & Conto "O banho" \\
\hline Ano I, no 6, dez. 1948. & $\begin{array}{l}\text { Crítica literária sobre as publicações dos } \\
\text { escritores cearenses no ano de } 1948 \text {. }\end{array}$ \\
\hline Ano II, no 7, fev. 1949. & $\begin{array}{l}\text { Crítica literária sobre as publicações dos } \\
\text { escritores cearenses no ano de } 1949 \text {. }\end{array}$ \\
\hline Ano II, no 8-9, abr. 1949. & $\begin{array}{l}\text { Crítica literária dos livros Janelas } \\
\text { entreabertas, de Lúcia Martins; } \\
\text { Latifúndio devorante, de Aluízio Alves; } \\
\text { Poesias, de Cruz Filho; e Apoemas, de } \\
\text { Mozart Soriano Aderaldo e José Stênio } \\
\text { Lopes. }\end{array}$ \\
\hline Ano IV, no 11, dez. 1951. & Artigo "Um ano de vida literária" sobre \\
\hline
\end{tabular}




\begin{tabular}{|l|l|}
\hline & $\begin{array}{l}\text { as publicações das Edições Clã. } \\
\text { Novela Longa é a noite }\end{array}$ \\
\hline Ano V, no 13, dez. 1952. & $\begin{array}{l}\text { Artigo "À margem dos 'Estudos de } \\
\text { Pedagogia' regional”. }\end{array}$ \\
\hline Ano VI, no 14, dez. 1953 & $\begin{array}{l}\text { Conto na coletânea "9 Contos" que } \\
\text { incluía Moreira Campos, Lúcia } \\
\text { Fernandes Martins, Artur Eduardo } \\
\text { Benevides, Eduardo Campos, Sinval de } \\
\text { Sá, Braga Montenegro, José Stênio Lopes } \\
\text { e Fran Martins. }\end{array}$ \\
\hline
\end{tabular}

Como é possível depreender dos quadros apresentados acima, JCB conquistou um capital simbólico relevante a partir do conjunto de capitais cultural, social e intelectual que o colocou em posição de relevo no campo intelectual da província, mas que também lhe proporcionou visibilidade em âmbito nacional e sua inserção em um espaço de sociabilidade que o conectou com Caio Prado Junior, Sergio Milliet e Sergio Buarque de Holanda, para citar apenas membros do "grupo dirigente" da $R B$.

A participação em uma rede de intelectuais de relativa abrangência nacional, tendo como base a cidade de São Paulo, deve-se ao fato dela ser formada em grande parte por agentes cujas trajetórias não se davam prioritariamente no campo científico, ainda em constituição no país, com o início da expansão das universidades para além do eixo Rio de Janeiro e São Paulo ${ }^{11}$. Embora Luís Carlos Jackson (2004) situe a $R B$ entre as revistas de cunho acadêmico dos anos de 1950, ele próprio reconhece que se tratava de uma publicação conectada aos campos cultural, acadêmico e político, dando vazão, por isso, a artigos políticos, de crítica cultural e de divulgação científica. Dessa forma, em um momento que a autonomia do campo científico era incipiente, a $R B$ configuravase, como outras publicações do gênero na época, como "híbrida".

$\mathrm{Na}$ prosopografia que fez com os participantes do manifesto de 1955, Sérgio Montalvão (2017) encontrou um predomínio de ensaístas, com atuação no jornalismo e sem pós-graduação, ou seja, com perfil de “intelectuais não especializados”. Aqueles que produziam a partir de um disciplina especializada eram da História ou da Medicina

\footnotetext{
11 A Universidade do Ceará, por exemplo, só foi instalada em 1955, ao reunir faculdades já existentes (Agronomia, Direito, Medicina, Farmácia e Odontologia) cujos professores eram, em grande maioria, sócios do Instituto Histórico do Ceará e/ou imortais da Academia Cearense de Letras.
} 
Social, não havendo qualquer representante das ciências físicas e naturais e revelando o viés humanista e cultural do periódico.

Portanto, em vez do circuito universitário, a sociabilidade era proporcionada por outras instituições, como as academias de letras e os institutos históricos, algumas criadas no século XIX, que, espalhadas pelo Brasil, estabeleciam um intenso intercâmbio entre seus membros. O Instituto Histórico, Geográfico e Antropológico do Ceará, por exemplo, foi fundado em 1887 e no mesmo ano iniciou a edição de sua Revista. Apesar de não ter pertencido aos quadros do Instituto, JCB contribuiu com artigos de cunho histórico para a referida publicação. Por sua vez, assumiu, em 1953, a cadeira 9 da Academia Cearense de Letras, a mais antiga do país, fundada em 1894 (a Academia Brasileira de Letras é de 1897). Soma-se a esse circuito há muito estabelecido entres estas instituições consagradas, aquele propiciado, a partir de 1942, pela criação da $\mathrm{ABE}$, com suas seções estaduais, os encontros nacionais e sua participação nos debates políticos e culturais do país.

Pode-se especular, por fim, e seguindo uma pista levantada por Machry (2017), que havia a necessidade da $R B$ de minimizar sua vinculação excessiva à São Paulo - um impasse para uma publicação voltada para questões acerca do nacionalismo - e de agregar intelectuais de outros estados brasileiros. Montalvão (2017) também chama atenção nesse sentido, ao apontar que a presença não desprezível de membros das regiões Norte, Nordeste e Centro-oeste era coerente com o projeto da revista. Mas adverte que muitos deles fizeram suas carreiras no Rio ou São Paulo, como o amazonense Abguar Bastos, o baiano Nabor Caires de Brito e o mato-grossense Heitor Ferreira Lima.

Em outras palavras, para "desregionalizar" ou superar o "regionalismo", os editores ampliaram a atuação da revista por outros estados, não apenas incorporando em sua fundação intelectuais ali atuantes, como recebendo artigos oriundos de todo o país. Contudo, ainda que sua participação denotasse o caráter político-cultural nacionalista da $R B$, grande parte dos membros fundadores teve uma participação modesta no quantitativo de artigos publicados, e mais, como resultado da lógica do poder no campo intelectual brasileiro, as decisões editoriais eram do grupo paulista.

Ocorreu, então, uma conjunção favorável entre a trajetória de JCB e o posicionamento "nacional" dos intelectuais paulistas ligados à Brasiliense. Estes, na busca por incluir representantes de outros estados, viram no romancista cearense, que não se destacava como um "pensador dos problemas brasileiros", mas era reconhecido 
no meio literário brasileiro e conectado com alguns dos fundadores da revista, um nome adequado ao projeto político-cultural da $R B$.

\section{Considerações finais}

As questões relativas aos intelectuais oriundos da e/ou atuantes na província são temas caros à sociologia da cultura, pois diz respeito, entre outras coisas, à forma como se exerce o poder simbólico em determinado contexto nacional ou mesmo internacional. No caso brasileiro, as enormes disparidades sociais, econômicas e culturais interregionais que se estabeleceram desde o Império tornam a temática ainda mais relevante, diante de fenômenos como, por exemplo, o fato de ter ocorrido na provinciana Fortaleza da segunda metade do século XIX, uma conjuntura propícia ao desenvolvimento intelectual da qual participaram pensadores que seria fundantes da história (Capistrano de Abreu), da filosofia (Farias Brito) e do direito (Clóvis Beviláqua) no país.

Fazendo referência de modo específico aos romancistas naturalistas, José Ramos Tinhorão adverte que na década de 1870 ocorreu uma série de movimentos intelectuais no Ceará que, além de ser "um dos mais curiosos capítulos da história da literatura brasileira", se coloca como "um dos mais sugestivos desafios à sua interpretação como fenômeno sociológico" (TINHORÃO, 2006: 19). Para o pesquisador, a questão se colocava era: como veio a se formar "numa província pobre do Império uma geração de homens capazes de discutir, no mesmo plano dos núcleos intelectuais da Corte, as mais recentes conquistas das ciências ou as últimas modas filosóficas ou literárias?" (TINHORÃO, 2006: 20).

Não foi esse o problema gerador do presente artigo, mas compartilha de um mesmo pano de fundo que se refere aos processos de formação, circulação, recrutamento e consagração dos intelectuais provincianos. Em outras palavras, acompanhar a trajetória de JCB, desde sua vinda do interior cearense até seu recrutamento pela $R B$, possibilita um melhor entendimento sobre o funcionamento das redes de sociabilidade, dos mecanismos de consagração e dos modos de participação político-cultural atuantes entre os intelectuais no Brasil dos anos 1950, a partir de um olhar descentrado.

\section{Fontes}

CORREIO DA MANHÃ, 1952.

REVISTA BRASILIENSE, n. 1, 1955. 


\section{Referências bibliográficas}

ADERALDO, Mozart Soriano (1986). História Literária do Ceará (Dos "Oiteiros" ao Grupo Clã). Revista do Instituto do Ceará, pp. 225-247.

(1981). Grupo CLÃ - 40 anos. Revista da Academia Cearense de Letras, pp. 225-247.

ALVES, Plauto (2015). O “fazer intelectual" brasileiro (1930-1946): Rachel de Queiroz e o Congresso de 1946. Dissertação (Mestrado em História). Universidade Estadual Paulista "Júlio de Mesquita Filho", São Paulo.

AZEVEDO, Sânzio de 91982). O Ceará e os grêmios literários. Rev. de Letras, Fortaleza, n. 5, v. 2, pp. 123-126.

BARBALHO, Alexandre (1998). Relações entre Estado e cultura no Brasil. Ijuí: Unijuí.

\& BARROSO, Oswald (org) (1998). Letras ao Sol. Antologia da literatura cearense. Fortaleza: Demócrito Rocha.

BARROSO, Oswald (1998). A modernidade na literatura cearense: dos Novos ao Grupo Siriará. In: BARBALHO, Alexandre\& BARROSO, Oswald (org). Letras ao Sol. Antologia da literatura cearense. Fortaleza: Demócrito Rocha, pp. 23-37.

BEZERRA, João Clímaco (1997). Não há estrelas no céu. Fortaleza: UFC.

BOUDIEU, Pierre (2005). Esboço de auto-análise. São Paulo, Cia das Letras. (1999). Le fonctionnement du champ intellectual. Regards Sociologiques, $\mathrm{n}^{\circ} 17 / 18$, pp. 5-27.

(1986). L'illusion biographique. Actes de la Recherche en Sciences Sociales, $\underline{62-}$ 63, pp. 69-72.

CALDAS, Renan Rubim (2015). O Brasil da Revista Brasiliense: perspectivas nacionalistas na escrita de Elias Chaves Neto (1955-1960). In: VANANCIO, Giselle Martins (org.). Intelectuais e palavra impressa. Niterói: UFF.

CÂMARA, José Bonifácio (1999). Personas. Notas de um bibliófilo cearense. Fortaleza: UFC.

CORREIO DA MANHÃ, Rio de Janeiro, 07 de outubro de 1952, $1^{\text {o. }}$ Caderno, p. 10 , $5^{\text {o. }}$ Caderno, Rio de Janeiro, 23 de novembro de 1952, p. 2.

FARIAS, Maria Auxiliadora (2003). Edições e seduções. Revista Clã: 1946-1957. Dissertação. (Mestrado em História). Universidade Federal de Pernambuco, 2003.

GARCIA JÚNIOR, Afrânio (2004). A dependência da política:isệ̉Fernando Henrique Cardoso e a sociologia no Brasil. Tempo Social, pp. 285-300.

JACKSON, Luiz Carlos (2004). A sociologia paulista nas revistas especializadas (19401965). Tempo Social, São Paulo, v. 16, n. 1, pp. 263-283.

LIMONGI, F M P (1987). Marxismo, nacionalismo e cultura: Caio Prado Júnior e a Revista Brasiliense. Revista Brasileira de Ciências Sociais, São Paulo, v. 5 , n. 2 , pp. 27-46.

MACEDO, Dimas (s/d). João Clímaco Bezerra: 2013 - 1913. Disponível em http://dimasmacedo.blogspot.com/2013/01/centenario-de-joao-climacobezerra.html. Acesso em: 09.dez.2020.

MACHRY, Marcos Santos (2017). O horizonte nacionalista de esquerda e a Revista Brasiliense (1955 - 1964): sociabilidade intelectual e linguagem política. Dissertação (Mestrado em História). Universidade Federal do Rio Grande do Sul. Porto Alegre.

(2011). Um olhar sobre a revolução cubana por meio dos escritos nacionalistas da Revista Brasiliense entre 1960 e 1963. Monografia (Licenciatura em História) Universidade Federal do Rio Grande do Sul. Porto Alegre. 
MELO, Ana Amélia de Moura C (2011). de. Associação Brasileira de Escritores: dinâmica de uma disputa. VARIA HISTORIA, Belo Horizonte, v. 27, n. 46, pp.711-732.

MELLO, Marisa Schincariol de (2019). Como se faz um clássico da literatura brasileira? Rio de Janeiro: Automática.

MONTALVÃO, Sérgio de Sousa (2017). História cruzadas: uma prosopografia dos fundadores da Revista Brasiliense (São Paulo, 1955). História, São Paulo, v.36, n. 7, pp. 01-28.

NOBRE, Thiago da Silva (2013). de Clã e a consolidação do campo literário de Fortaleza na década de 40. Monografia (Graduação em História). Universidade Estadual do Ceará, Fortaleza.

OLIVEIRA, Erich Soares de (2019). Os intelectuais e a cultura: o itinerário editorial de afirmação da geração cearense de 1940 (1938-1953). Dissertação (Mestrado em Sociologia). Universidade Federal do Ceará, Fortaleza.

PÉCAUT, Daniel (1990). Os intelectuais e a política no Brasil. Entre o povo e a nação. São Paulo: Ática.

PEREIRA, Raul (2017). Clube de cinema de Fortaleza: sociabilidade intelectual e cultura cinematográfica na cidade de Fortaleza (1948-1963). Dissertação (mestrado em História). Universidade Federal do Ceará, Fortaleza.

PEREZ, Renard. Escritores brasileiros contemporâneos. João Clímaco Bezerra. Correio da Manhã, Rio de Janeiro, 17 de novembro de 1956, $1^{\text {o. }}$ Caderno, p. 10.

RUBIM, Albino (1995). Marxismo, cultura e intelectuais no Brasil. Salvador: UFBA.

SANTANA, Carla Patrícia Bispo de (2003). estreia de Heron de Alencar como crítico literário no jornal A Tarde (19471952). Dissertação (Mestrado em Letras). Universidade Federal da Bahia, Salvador.

SANTOS, Eduardo Oliveira dos (2016). Intelectuais comunistas e a Revista Fundamentos: afirmação e atenuações das diretrizes partidárias (1948-1955). Dissertação (Mestrado em História). Universidade Federal Rural do Rio de Janeiro, Rio de Janeiro.

SAPIRO, Gisèle (2009). Modèles d'intervention politique des intellectuels. Le cas français. Actes de la Recherche en Sciences Sociales, Paris, n. 176-177 pp. 8-31.

SILVA, Anderson de Sousa (2015). O Salão de Abril em dois momentos: Sociedade Cearense de Artes Plásticas (SCAP) e Prefeitura Municipal de Fortaleza (1944 1970). Dissertação (Mestrado em História). Universidade Federal do Ceará, Fortaleza.

SORA, Gustavo (2011). A arte da amizade: José Olympio, o campo de poder e a publicação de livros autenticamente brasileiros. Antropolítica, Niterói, n. 30, pp. 49-71.

TINHORÃO, José Ramos (2006). A província e o naturalismo. Edição fac-similar. Fortaleza, NUDOC.

ZPREK, Bruno (2007). Concepções de sujeito e objeto do conhecimento na obra histórica de Caio Prado Jr. Dissertação (Mestrado em História). Universidade Federal do Rio Grande do Sul. Porto Alegre.

Artigo recebido em 4 de março de 2021.

Artigo aprovado em 3 de junho de 2021

DOI: $10.12957 /$ intellectus.2021.58162 